\title{
LAS ORGANIZACIONES INTERNACIONALES Y LOS NUEVOS DESAFIOS GLOBALES
}

\author{
Rafael Grasa \\ Profesor de Relaciones Internacionales \\ Facultat de Ciencies Politiques i de Sociologia \\ Universitat Autònoma de Barcelona
}

Resum

L'article s'ocupa d'una de les manifestaciones del creixent fenomen d'organització internacional, la creació d'organitzacions internacionals. Es parteix de la distinció entre "organitzacio" ja perceptible a la Grècia clàssica, $i$ "organitzacions", que neixen a consequiencia del sistema internacional sorgit del Congrés de Viena. En segon lloc, es presenta una definició operativa d'organitzacions internacionals i s'estableix una tipologia en funció de quatre criteris de classificació: la naturalesa jurídico-politica dels membres; la composició i abast de l'organització; els objectius i camp d'actuació, i l'estructura i model organitzatiu. En tercer lloc, s'analitzen les funcions de les organitzacions intergovernamentals (OIGs) com actors internacionals, bé com a instruments dels estats o, pel contrari, com modificadors de la seva conducta, bé com a subjectes autònoms de les relacions internacionals. Finalment, s'estudia la possibilitat que les OIGs esdevinguin gestors dels grans problemes globals amb dimensió internacional, particularment el canvi climàtic i la degradació mediambiental, tot prenent com exemple la preparació $i$ resultats de la cimera de Rto de Janeiro.

Resumen

El articulo se ocupa de una de las consecuencias del creciente fenómeno de organización internacional, la creación de organizaciones internacionales. Se parte de la distinción entre "organización", ya perceptible en la Grecia clásica, y "organizaciones", cuyo nacimiento está ligado al sistema internacional surgido del Congreso de Viena. En segundo lugar, se presenta una definición operativa de "organizaciones internacionales" y se establece una tipologia en función de cuatro criterios de clasificacion: la naturaleza jurídico-politica de sus miembros: la composición y alcance de la organización; los objetivos y campo de actuación, $y$ la estructura y modelo organizativo. En tercer lugar, se analizan las funciones de las organizactones intergubernamentales (OIGs) como actores internacionales, bien como instrumentos de los estados o, por el contrario, como modificadores de su conducta, bien como sujetos autónomos de las relaciones internacionales. Por último, se estudia la posibilidad de que las $O / G$ se conviertan en gestores de los grandes problemas globales con dimensión internacional, parti- 
"Papers": Revista de Sociologia

cularmente el cambio climático y la degradación ambiental, tomando como ejemplo la preparación y resultados de la cumbre de Rio de Janeiro.

Abstract

The article deals with one of the outcomes of the growing international organization process, which is the creation of international organizations. The starting point is the distinction between "organization", already present in classical Greece, in the states-system of Hellas, and "organizations", whose origin is bound to the international system arising from the Congress of Vienna. Secondly, a working definition of uinternational organizations" is put forward and a tipology based on four criteria of classification is established. These are: the legal-political nature of its membership; the character and scope of the organization; its aims and purposes, and its structure and organization. Throlly, comes the analysis of the functions of intergovernmental organizations (IGOS) as international actors, either as insiruments of the state (or, contrarily, as modifyers of the state's conduct); or as autonomous subjects in intermational relations. Lastly, attention is given so the prospects of IGOS becoming managers of international global issues of international dimension; notably, clmatic change and environmental degradation, taking the preparation and outcomes of the Rio summit as an example of this.

El sistema internacional se catacteriza, como puede verse en el artículo de García en este mismo número de Papers, por la existencia de diversos actores (con predominio de los estados), por la desigual distribución de poder y capacidades que rige los flujos de interacción entre esos actores, y por la inexistencia de tina autoridad legítimamente designada y reconocida por todos ellos, capaz de imponer una organización colectiva y de gobetnar. Sin embargo, esta última característica, a la que a menudo se alude mediante la expresión "anarquía del sistema internacional", no es en modo alguno incompatible con la existencia de regtalaridades y de orden.

En efecto, aunque los actores no se interrelacionan en condiciones de paridad absoluta ni de acuerdo con procedimientos estipulados en un "contrato" previo, sus conductas e interacciones - las relaciones internacionales- ni son cabticas ni responden al simple azar. Se observan, por el contrario, ciertas reglas (convenciones, principios y reglas de juego) y operan ciertas instituciones (conjuntos de procedimientos, reglamentos y, a veces, organizaciones) mediante las cuales los actores - y muy en particular los estados - intentan gestionar problemas comunes.

De ahí que pueda caracterizarse la historia de las relaciones internacionales como un fenómeno de creciente organización internacional, una de cuyas manifestaciones específicas es el surgimiento de organizaciones internacionales concretas. Por decirlo con unas palabras ya clásicas, "la organización internacional es un proceso; las organizaciones internacionales constituyen aspectos 
representativos del estadio que ese proceso ha alcanzado en un momento dadon (Claude, 1964: 4).

\section{ORGANIZACION INTERNACIONAL VERSUS ORGANIZACIONES INTERNACIONALES}

La distinción de Claude entre organización y organizaciones nos va a servir para establecer algunas precisiones conceptuales $y$ atgunas referencias históricas que eviten la confusión derivada del uso aparentemente sinónimo que atgunos autores y manuales hacen de las expresiones «instituciones" y "organizaciones" internacionales.

La confusión proviene del doble uso que se ha dado a la palabra «institución" o «instituciones» sociales: a) un concepto que describe ciertas pautas de conducta sancionadas o aprobadas, es decir, un conjunto de normas, costumbres o leyes que constituyen formas regularizadas de resolver ciertos problemas sociales (lo que incluye, obviamente, problemas internacionales); b) una estructura con una forma organizativa concreta, con existencia material y tangible, que a menudo puede incluir personal específico. Obviamente, en el primer caso el significado de la palabra es mucho más amplio que en el segundo. Dicho de otra forma, al hablar de instituciones (sociales, internacionales) en el sentido de formas organizativas concretas se presupone necesariamente la existencia de formas de conducta pautadas. No sucede lo mismo en eí caso inverso: puede haber instituciones sin que ello suponga necesariamente el establecimiento de fórmulas organizativas especificas (organizaciones).

Así, cuando Claude afirma que el proceso de «organización internacional» es un rasgo característico de las relaciones internacionales está aludiendo a la existencia de "instituciones» internacionales en la primera acepción del término, como reflejo o indicador de las regularidades aprehensibles en la conducra e interacciones de los diversos actores. En ese sentido, la organización internacional (la existencia de instituciones no necesariamente estructuradas organizativamente, que ordenan las pautas de relación entre los actores internacionales) es un fenómeno constatable desde hace bastantes siglos en las relaciones internacionales, al menos episódicamente. Podrá afirmarse que existe "organización inrernacional" siempre que haya un grupo de estados (y de actores no estatales, a partir del momento en que éstos sean significativos) que disponga de mecanismos de diálogo regulares y de ciertos arreglos comunes para reglar sus relaciones, así como voluntad de mantener ambas cosas por considerarlas convenientes para sus respectivos intereses.

Un buen ejemplo de ello sería la Grecia clásica y su sistema de estados, dándole a "estados" un significado amplio, puesto que en su sentido moderno, 
como recuerda Barbé en este mismo número, no aparecen hasta el Renacimiento. El orden, la organización del sistema de estados greco-clásico, provenía de la existencia de varios elementos: instituciones panhelénicas (los juegos olímpicos, el oráculo de Delfos), las ligas de ciudades-estado y procedimientos de resolución pacífica de las controversias y, por último, mecanismos de representación consular y negociación diplomática relativamente estables (Whight 1977: 46-72; Watson 1992). Otro ejemplo podría ser, obviamente, el moderno sistema de estados europeo, surgido a partir del Congreso de Westfalia (1648) y el tratado de Utrecht (1713), cristalización del paso del unitarismo de la cristiandad a la diversidad de una Europa secular de potencias soberanas independientes. En dicho sistema, la organización internacional constituía un prerrequisito de funcionamiento (Taylor/Groom, 1988: 11).

Por el contrario, la creación de "instituciones internacionales" en la segunda acepción del término (la restringida, sinónima de organizaciones internacionales), es un fenómeno mucho más reciente, habida cuenta de que presupone el establecimiento de estructuras organizativas con existencia formal y material separada -aunque no independiente- de los estados y agrupaciones de estados (Archer, 1992: 3). En teoría, los gobiernos hubieran podido crear una red de organizaciones internacionales a partir del siglo XVIII, es decir, a partir de la consolidación del sistema westfaliano de estados soberanos. No obstante, lo cierto es que la historia de las relaciones internacionales muestra que se requiere un alto grado de organización internacional para que surjan organizaciones internacionales estables.

En particular, tal fenómeno resulta impensable sin que se cumplan cuatro condiciones (Claude, 1964: 17): a) la existencia de un número suficiente de estados que funcionen como unidades políticas independientes; b) un alto grado de contacto regular (comercial, económico, político-diplomático, etcétera) entre tales unidades; c) conciencia de los problemas que se derivan de la coexistencia de esos diversos estados en zonas geográficas contiguas; y d) aceptación de la necesidad de crear procedimientos institucionales y métodos sistemáticos para regular las relaciones recíprocas y, sobre todo, los problemas compartidos.

Tales condiciones, y en especial las dos últimas, no se darán hasta el siglo XIX, merced a los cambios político-diplomáticos surgidos del Congreso de Viena (1815), el posterior sistema de conciertos, su progresiva internacionalización (es decir, su ampliación allende las fronteras continentales) y las modificaciones derivadas de las conferencias de limitación de armamentos y desarme de La Haya $(1899,1907)$. Vamos a ocuparnos brevemente de las consecuencias de todos estos cambios.

Hay que destacar, en primer lugar, el incremento de la interacción regular y pautada entre los estados por razones políticas. Concretamente, el Congre- 
so de Viena codificó las reglas de la diplomacia, convirtiéndola en una actividad que se ejercitaba no sólo en provecho de los estados particulares sino también del sistema. El concierto europeo supuso, por su parte, la institucionalización de compromisos entre los estados con vistas a resolver las amenazas a la estabilidad; así, de acuerdo con el artículo VI del tratado de Chaumont, las potencias firmantes se comprometían a encontrarse de forma regular, bien a nivel de soberanos bien a nivel de ministros. Pronto menudearon las conferencias internacionales entre las grandes potencias europeas (Austria, Francia, Inglaterra, Prusia y Rusia; posteriormente, Alemania e Italia) y, eventualmente, pequeñas potencias implicadas en los asuntos a discutir. Por último, las conferencias de La Haya significaron el primer intento de establecer regulaciones en parcelas especialmente sensibles para la soberanía nacional como el armamento.

A resultas de todo ello, reunirse para tratar de cuestiones de "alta política" se convirtió en un hábito en el continente europeo. A veces se trataba de resolver guerras, como en las conferencias posteriores a un conflicro, entre ellas: la conferencia de paz de París tras la guerra de Crimea (1856); la de Viena acerca del conflicto Schleswig-Holstein (1864), la de Praga a propósito de la guerra de las siete semanas (1866) o la de Frankfurt, destinada a ocuparse de la guerra franco-prusiana (1871). En otras ocasiones, el objetivo era cooperar en la búsqueda de la paz, gestionando conflictos susceptibles de provocar enfrentamientos armados: la cuestión de los Balcanes tras la guerra ruso-turca (Congreso de Berlín, 1878); el reparto de la colonización de Africa (Congreso de Berlín, 1884-1885); o la disminución de las tensiones a propósito de las rivalidades en el norte de África (Conferencia de Algeciras, 1906).

En cuanto a la internacionalización del sistema europeo, es decir a la expansión de sus reglas al resto del planeta, bastará con recordar algunos hechos acaecidos entre finales del siglo XVIII y mediados del XIX. A saber: el Tratado de París (1783), que supuso el reconocimiento internacional de los Estados Unidos de América; el reconocimiento británico de los nuevos estados latinoamericanos (1823); la admisión del Imperio otomano (y de Rumanía) en el sisterna europeo (Tratado de París, 1856); la adhesión de Japón al sistema tras la presión estadounidense (1853); la imposición a China de relaciones diplomáticas y tratados desiguales por parte de Gran Bretaña (mediados del siglo XIX).

En paralelo al proceso de creciente interacción y alcance de las actividades políticas interestatales, se constata un proceso de interacción técnico-económica (es decir, en la esfera de la "política menor» o low politics). En efecto, la extensión de las actividades económicas de los estados, el incremento e internacionalización de las prácticas comerciales y económicas, así como los cambios cientificos y tecnológicos en el terreno de los transportes (navegación a vapor, ferrocarriles) y comunicaciones (telégrafo), impelieron a los estados a 
"Papers": Revista de Sociologia

coordinar su acción en las áreas técnicas y socio-económicas mediante convenios o tratados y a crear, para ello, organizaciones específicas. "El sistema de administraciones nacionales se había quedado completamente obsoleto, incapaz de habérselas con la realidad moderna de fletes y comercio internacional" (Woolf, 1916: 373).

Como consecuencia de todo ello, surgirían a lo largo del siglo Xix las comisiones y uniones internacionales, los dos grandes tipos de organizaciones internacionales del siglo pasado, junto a las «organizaciones cuasi-coloniales temporales" (Reuter, 1958: 207) ${ }^{1}$. Comisiones y uniones instauraron formas específicas y regladas de cooperación técnica entre estados, incluyendo secretariados permanentes dotados de un mínimo funcionariado internacional, una característica que luego se desarrollará notoriamente a lo largo del siglo XX.

El fenómeno, empero, no debe interpretarse como fruto de una voluntad altruista, como renuncia a la soberanía. Responde a la "utilización de los recursos de la soberanía para crear instituciones y métodos capaces de apoyar la actividad funcional de los gobiernos nacionales. La creación de las uniones públicas internacionales constiruía una muestra del reconocimiento de la inadecuación funcional de la soberanía y de las ventajas de agruparse para compensar dicha inadecuación" (Claude, 1964: 40).

La principal tarea de las primeras comisiones internacionales (Comisiones Internacionales parà la Navegación por el Rhin, el Elba, el Escalda y el Mosa, y el Danubio, establecidas respectivamente en $1815,1821,1839$ y 1856) consistió en posibilitar el ejercicio del principio de libre navegación comercial por los ríos internacionales adoptado en el Congreso de Viena. Por su parte, las uniones administrativas (por ejemplo, la Unión Telegráfica Internacional, la Unión Postal Universal, la Oficina Internacional de Pesos y Medidas o la Unión para el sistema métrico, creadas respectivamente en 1868, 1874 y 1875) respondían a la necesidad de establecer grupos de expertos y administradores que coordinaran los cambios provocados por la propagación allende de las fronteras de numerosas innovaciones técnicas. Un ejemplo claro es el del sello postal, inventado en Gran Bretaña (1837) y rápidamente adoptado en muchos otros países, pronto se ensayaron procedimientos de coordinación bilaterales, multilaterales y regionales, hasta que en 1874 se creó la unión (1874). Inicialmente se la denominó Unión General Postal, pero pronto se sussituyó "general" por "universal" para mostrar la interdependencia de los diversos países del mundo (Colliard, 1985: capítulo 2).

1. Fs decir, arreglos institucionales de corta vida derivados de los acuerdos de varios estados europeos para facilitar o supervisar servicios en áreas como finanzas o salud pública que las autoridades no europeas de zonas del imperio otomano o China no podían proveer por sí solas. Su importancia, empero, es sobre todo historica, como precedente del sisterna de mandatos de la Sociedad de Naciones o de los fideicomisos de las Naciones Unidas. 
Paralelamente al desarrollo de las uniones técnico-administrativas durante la segunda mitad del siglo XIX, surgirán también numerosas iniciativas, congresos periódicos y asociaciones internacionales de índole privada (es decir, no estatal), que a menudo establecerán también secretariados y diversas formas de institucionalización permanente. Destacan especialmente las iniciativas en el terreno humanitario, religioso, económico, educativo, cientifico y político. Entre ellas, y casi al azar, podemos destacar las siguientes: el Congreso Mundial en Contra de la Esclavitud, el Congreso en pro de la Paz Universal, el Instituto Internacional de Agricultura, la Asociación de Derecho Internacional, el Comité Internacional de La Cruz Roja o la Asociación Internacional de Protección Legal del Trabajo.

Muy pronto, además, se producirá una relación simbiótica — no exenta de conflictos-entre las asociaciones internacionales públicas.y privadas. Una de sus consecutencias será la aparición de organizaciones mixtas, es decir, organizaciones que combinan la presencia de miembros individuales (privados) y representantes gubernamentales (miembros públicos).

En sintesis, durante el siglo XIX el proceso de organización internacional experimenta avances notorios en el terreno de la "alta política" (paz, guerra, seguridad) y de la "política menor" (cuestiones técnico-económicas). El proceso afecta sobre todo al continente europeo, aunque cabe destacar los significativos avances en el continente americano (incluyendo América Latina). En efecto, pese al fracaso de los primeros intentos serios de fomentar la organización internacional regional (Congreso de Panamá, 1826), a finales de siglo ya se reúne regularmente el Congreso de Estados Americanos, y en 1910 la Unión Panamericana se encarga de asuntos técnicos, políticos, culturales y administrativos (Taylor/Groom, 1988: 14). Tanto en Europa como América se irá acumulando experiencia de cooperación intergubernamental que, en la medida en que resulta beneficiosa para las diversas partes implicadas, refuerza la convicción ideológica de su necesidad. Como consecuencia de la mayor organización internacional y del reconocimiento de la necesidad de cooperar en las esferas en que existe una "inadecuación funcional de las soberania», surgen numerosas organizaciones internacionales, gubernamentales (públicas) y no gubernamentales (privadas): en 1909 se habían censado ya treinta y siete organizaciones internacionales de tipo gubernamental y ciento setenta y seis no gubernamentales (Archer, 1992: 14) ${ }^{2}$.

La tendencia al incremento de la organización internacional y al auge numérico de las organizaciones internacionales proseguirá de forma constante a lo largo del siglo $\mathrm{xx}$, al igual que la expansión de ambos fenómenos (como aspi-

2. El único registro fiable de las organizaciones internacionales gubernamentales y no gubernamentales está incluida en el Yearbook of International Organizations, publicación anual de la Union of International Associations (creada en 1910). 
ración y como realidad) fuera del continente europeo. En lo que respecta a las organizaciones internacionales, un fenómeno relativamente nuevo pero de crecimiento rápido, la experiencia acumulada y la convicción ideológica harán que el fenómeno sobreviva al sistema europeo de estados en que nació y a los diversos cambios de sistema internacional acaecidos desde entonces. De hecho, no sólo sobrevivirá a dichos cambios sino que experimentará un importante acelerón tras los cambios de sistema provocados por la I y la II guerra mundiales.

No obstante, el ya mencionado auge numérico de las organizaciones internacionales y, por tanto, su progresiva heterogeneidad, plantea un problema intelectual: definirlas con más precisión, establecer principios clasificatorios y tipologías, así como pautas genéricas que faciliten su análisis como actores de las relaciones internacionales. No en vano el estudio de la organización internacional y el de las organizaciones internacionales específicas constituye en la actualidad una de las subáreas de trabajo de la disciplina de las Relaciones Internacionales, con una publicación periódica especializada desde hace más de cuarenta años, International Organization ${ }^{3}$.

\section{DEFINICION, TIPOLOGIA Y ESTRUCTURA DE LAS OIS}

Pese a ello, o quizás a causa de ello, no existe nada parecido a una definición estándar de qué se entiende por "organizaciones internacionales" (OI). De ahí que al consultar diccionarios especializados, manuales de relaciones internacionales o de derecho internacional público, o bien anuarios u obras específicamente dedicadas a las OIs, menudeen las definiciones muy diferentes o, por el contrario, resulte imposible encontrar una definición explícita. Otras veces, las definiciones o son demasiado genéricas (por ejemplo, cuando se dice simplemente que una OI es un actor no estatal) o incluyen referencias problemáticas a términos confusos o también difíciles de precisar, como sucede con la definición de Osmanczyk: "cualquier asociación o institución pública que reúna a personas físicas o legales de al menos tres países, sujeta al derecho de las organizaciones internacionales" (Osmanczyk, 1990: 657).

Por todo ello algunos autores (Archer, 1992), a quien seguiremos, han propuesto un método diferente. Primero, singularizar los rasgos comunes presentes en buena parte de las definiciones al uso (es decir, los rasgos definitorios que se consideran prerrequisitos para poder calificar a una institución internacional como $\mathrm{OI}$ ); posteriormente, establecer a partir de ellos una mera

3. La revista se fundó en 1947, por lo que un estudio de contenido de los artículos publicados en ella permite tener una visión bastante clara de la evolución de la subárea. Véase como ejemplo el análisis de F. Kratochwill y J. Ruggie, uInternational Organization: A State of the Art on an Art of the State", International Organization, vol. XL, 1986, ntim. 4. 
definición operativa. Podemos destacar cuatro tipos de rasgos o exigencias presentes en la mayoría de definiciones propuestas, a saber:

a) en cuanto a la naturaleza y status formal de las OIs, que tengan carácrer permanente o estable y cierto grado de personalidad legal internacional;

b) respecto del número y tipo de miembros, que pertenezcan al menos a dos o tres estados (en calidad de representantes privados o públicos) y que se adquiera tal condición de forma voluntaria;

c) a propósito de los objetivos, que no persigan explícitamente el interés particular de uno de sus miembros, sino el interés común de todos eilos, excluyendo los intereses orientados a firalidades lucrativas (lo que impide considerar como OI instituciones como las empresas multinacionales o transnacionales, los carteles económicos, etcétera);

d) acerca de su estructura y organización, que exista un tratado, acuerdo o carta fundacional que establezca una estructura formal con voluntad de continuidad e imposible de controlar por uno sólo de sus miembros, así como una mínima estructura autónoma permanente (a diferencia de lo que sucede con los congresos internacionales o las conferencias diplomáticas).

De acuerdo con lo anterior, y ampliando significativamente una propuesta reciente (Archer 1992: 37), definiremos una OI como una estructuxa organizativa formal y permanente, independiente de sus miembros y con naturaleza jurídica precisa, establecida por acuerdo explícito y público entre sus miembros (gubernamentales y/o no gubernamentales), pertenecientes a dos - más estados soberanos, cuya finalidad consista en perseguir objetivos que beneficien los intereses comunes de sus respectivos miembros.

La mayoría de las características o rasgos distintivos que acabamos de utilizar para establecer la definición operativa de OI nos van a servir tambiérn para establecer criterios de clasificación que, al combinarse, permiten establecer diversas tipologías de las OIs. Puesto que tampoco existe consenso generalizado respecto de los criterios taxonómicos, de los muchos posibles (tamaño, affliación, ámbito y localización geográfica, funciones, propósitos, etc.), optaremos por los cuatro siguientes (combinando criterios de Archer 1992, Merle 1988 y Taylor Ph. 1984), que admiten, a su vez, nuevas subdivisiones:

1) la naturaleza jurídico-política de los miembros;

2) la composición y alcance de sus miembros (reales y porenciales) en relación al sistema internacional en su conjunto;

3) los objetivos y campo de actuación de la organización;

4) la estructura y modelo organizativo. 
"Papers»: Revista de Sociologia

Si atendemos a la naturaleza jurídico-política de los miembros, la distinción por excelencia es la que diferencia entre organizaciones formadas por miembros exclusivamente públicos, exclusivamente privados o bien organizaciones de composición mixta. Las organizaciones con miembros exclusivamente públicos - es decir, las formadas por acuerdos intergubernamentales o interestatales - reciben el nombre genérico de organizaciones intergubernamentales (OIGs) ${ }^{4}$. Entre los ejemplos clásicos pueden citarse las uniones administrativas, la Sociedad de Naciones o las Naciones Unidas, la Comunidad Económica Europea (CEE) o la Organización del Tratado del Attántico Norte (OTAN).

Por su parte, las formadas exclusivamente por miembros privados -es decir, las creadas por acuerdos de naturaleza no gubernamental- se denominan organizaciones no gubernamentales $(\mathrm{ONGs})$. Puede haber de diferentes tipos, pero habitualmente están formadas por representantes de agrupaciones pertenecientes a dos o más países. Pueden servir de ejemplo el Comité Inter-" nacional Olímpico, estudiado por Sureda en este mismo número de Papers, el Consejo Mundial de Iglesias, Amnistia Internacional o la Asociación Esperantista Mundial.

En la tercera categoría, la de las OIs de composición mixta, podemos situar algunos casos relativamente atípicos, en particular los dos siguientes: a) las organizaciones de origen intergubernamental que, sin embargo, aceptan a miembros que sin ser estados soberanos disponen de gobierno, como sucede en la Unión Internacional de Comunicaciones (aunque con la categoría de miembros asociados); b) aquellas organizaciones que, pese a ser claramente OIGs o ONGs si sólo se atiende a sus condiciones de creación, establecen que cada miembro zendrá una doble representación, gubernamental y no gubernamental, como sucede con la Organización Internacional del Trabajo o el Consejo Internacional de Uniones Científicas.

Fijémonos ahora en el segundo criterio, la composición y alcance de sus miembros, es decir, en el área del sistema internacional que los miembros de las diversas Ols cubren (composición real en un momento dado) y, sobre todo, en la que pueden llegar a cubrir en función de su campo de acción previsto, de sus aspiraciones (composición potencial máxima).

En este caso, tanto las OIGs como las ONGs pueden subdividirse en dos grandes categorías: a) organizaciones con un número limitado de miembros, a las que se suele denominar OrGs/ONGs regionales 0 , si conviene estrechar aún más el área de estudio, subregionales (por ejemplo, la

4. Aunque podría diferenciarse entre organizaciones internacionales públicas intergubernamentales e interestatales, dada la escasa importancia de la distinción, a efectos prácticos no la tendremos en cuenta. 
Organización de Estados Americanos o la Unión Árabe de Cámaras de Comercio); y b) organizaciones con un número potencial de miembros ilimitado, es decir, OIGs/ONGs a las que podemos calificar de universales (o también, globales, generales), en la medida en que pueden acoger como miembros a cualquier estado soberano. Naturalmente, la Organización de las Naciones Unidas (ONU) y muchos de sus organismos especializados entran en esta categoría, puesto que casi todos los estados soberanos existentes son miembros.

No obstante, ninguna de ambas categorías debe tomarse en sentido literal. Por ejemplo, no siempre es fácil decir con precisión donde acaba y empieza una región, puesto que al definirla se mezclan a menudo criterios geográficos y extrageográficos. De ahí que hasta el presente la Organización para la Unidad Africana (OUA) haya excluido a Sudáfrica por razones políticas o que no sean miembros de la OEA ni Canadá ni algunos estados del Caribe y, sin embargo, lo sean los Estados Unidos de América. Más allá de los problemas de definición, las "regiones" tampoco pueden considerarse elementos estáticos, inamovibles, como muestran las transformaciones de los mapas políticos europeos derivadas de la desaparición del bloque del Este.

Respecto de la categoría de Ol «universal», basta con señalar que si bien el calificativo "universal» tiene por lo general connotaciones descriptivas (por ejemplo, aplicado a la ONU), en algunos casos también puede tener valor desiderativo, (cuando se habla de una OIG que actuará como gobierno mundial). De ahí que algunos autores hayan propuesto una denominación más prudente, OIGs/ONGs suprarregionales (Taylor Ph. 1984: 20-21).

En conclusión, al menos en el campo de las OIGs, las organizaciones regionales y generales son, en la actualidad, complementarias, como muestran numerosas referencias de la Carta de las Naciones Unidas a los acuerdos u organismos regionales (por ejemplo, los artículos $23,33,47$ y 52).

Llegamos así al tercer criterio clasificador, los objetivos y campo de actuación de la organización. Habida cuenta del número actual de OIs (varios miles) y de su gran heterogeneidad, la gama de objetivos y actuaciones posibles, que van de lo más general a lo más especifico, es enorme y cambiante. Respecto del dinamismo, conviene señalar que depende al menos de dos factores: a) la propia evolución del sistema internacional y de la tendencia a una mayor organización de éste, cuyo ejemplo más claro es el incremento progresivo de las Ols (en particular las OIGs) de naturaleza política, casi insigniffcantes hasta el período de entreguerras en comparación con las OIGs técnico-económicas; b) la posibilidad que los propios documentos constitutivos permiten a algunas OIGs de ampliar o desarrollar sus objetivos y actividades que los propios documentos constitutivos permiten a algunas OIGs. 
De todo lo anterior se desprende que son numerosisimas las posibilidades y propuestas de clasificación. Para simplificar nos limitaremos a las dos grandes alternativas (Archer, 1992: 53-59).

La primera consiste en partir de una escala "general-específico" en que cabrían todas las áreas de actividad posibles de las diversas OIs existentes, escala en la que podríamos situar las actividades específicas de que se ocupa (o puede ocuparse) cada $\mathrm{OI}$ concreta en virtud de su acuerdo fundacional y de sus eventuales modificaciones). De esta forma, el problema clasificatorio se traslada a la forma de establecer dicha escala de actividades generales-específicas de las OIGs.

De las muchas posibilidades destacaremos, ordenadas de menor a mayor número de divisiones en la escala "general-específico", las siguientes:

a) organizaciones generales o especializadas;

b) Ols básicamente técnicas of fundamentalmente políticas;

c) predominantemente políticas, económicas, culturales, o de seguridad;

d) prioritariamente políticas, económicas, sanitarias, religioso-culturales, sociales, laborales, de defensa y seguridad, de transportes y comunicaciones, etcérera.

Estos criterios permitirían comparar, por ejemplo, organizaciones pertenecientes a ámbitos regionales toral o parcialmente coincidentes. Así, el Consejo Nórdico (tratados de 1962 y 1971) tendría un ámbito de actividad mayor que el de la Asociación Europea de Libre Cambio (EFTA, Convención de Estocolmo de 1960): aunque comparten objetivos en el área política y económico-comercial, ni el Consejo no se ocupa de algunas cuestiones técnicas (pesca o agriculrura) ni la EFTA de actividades en el campo de la cultura, la educación o la ciencia.

La segunda alternativa de clasificar las OIs en función de su campo de actividad es más abstracta: establecer tipos en función de las grandes orientaciones que subyacen a las diversas posibilidades de actuación internacional que pueden ejercer las OIGs. De acuerdo con Cantori y Spiegel, todas las acrividades especificas de las OIGs caben en una o varias de las siguientes orientaciones: a) alentar la cooperación entre los miembros (sería el caso de los objetivos explícitos de la ONU, la Liga Árabe, la OTAN, el Fondo Monetario Internacional/FMI, la EFTA o el Consejo Nórdico; b) desalentar la conflictividad entre los miembros, fomentando la prevención y gestión de los conflictos (ONU, Liga Árabe, OTAN, FMI); c) establecer pautas o procedimientos para una eventual confrontación entre miembros con opiniones diferentes o bien entre miembros de la OIGs y estados no pertenecientes a ella (ONU, capítulo VII de la Carta; Liga Árabe, anexo a propósito de Palestina). 
En cualquier caso, la propuesta de Cantori y Spiegel nos recuerda que las dos grandes pautas de interacción entre actores internacionales, la cooperación y el conflicto, valen también para las organizaciones internacionales.

Llegamos al último, y más complejo, de los criterios de clasificación, la estructura y modelos organizativos elegidos. La complejidad está relacionada con la heterogeneidad, una vez más, y con la progresiva complicación de los modelos y estructuras organizativas a medida que crecía el número de OIs y sus objetivos y campos de actuación. Una buena muestra de ello es la representación esquemática de cuatro modelos básicos que recoge la figura 1 (pág. 68). Aunque tienen génesis diferentes y persiguen diferentes intencionalidades, puesto que la disputa por el modelo no responde a meras disquisiciones técnicas o de eficacia administrariva, sino a una dererminada correlación de fuerzas o a determinadas premisas políticas (sobre todo en el caso de OIGs con actividades políticas), coexisten todavía.

Pese a la mencionada heterogeneidad, es posible encontrar algunos rasgos comunes en la estructura organizativa de las OIGS, una, digamos, estructura túpica, la más frecuente (Taylor Ph. 1984: cap. 2), pese a la existencia de numerosas excepciones. Esa estructura (véase figura 2 en pág. 69) suele constar de un consejo, un secretariado $y$, a veces, de un cuerpo ejecutivo o comisión, del que pueden depender diversos comités. Con menor frecuencia, bastantes OlGs cuentan con una asamblea o parlamento, un comité económico y social, y un tribunal encargado de dirimir disputas y/o interpretar las provisiones de la carta fundacional.

Al Consejo le suete corresponder la función decisoria de la organización, por lo que representa la suprema autoridad de la OIG y la voluntad colectiva de sus estados miembros. Lo habitual es que esté compuesto por funcionarios de rango ministerial (o sus suplentes) de rodos o algunos de los países miembros, aunque a veces puede reunirse en cumbres de los jefes de estado o gobierno, como sucede en la Organización para la Unidad Africana o en la OTAN (Consejo Atlántico). El Secretariado, que suele estar ubicado en la ciudad que sirve de sede a la OIG, es el órgano administrativo, en general sin poderes políticos, aunque la visibilidad y continuidad del cargo de secretario general, de existir, le confiere en algunos casos un papel político muy relevante (ONU). La Comisión o cuerpo ejecutivo, si existe, se encarga de elaborar los programas y ejecutar las políticas de la organización, por lo que suele contar con numerosos comités permanentes y grupos ad hoc que le auxilian en sus funciones.

En cuanto a los órganos o instituciones que Taylor considera simplemente comunes a muchas OIGs, la Asamblea o Parlamento, no desempeña, de existir, tareas legislativas, sino de asesoramiento y en algunos casos de control; lo normal es que no exista obligación de que el Consejo implique a la Asamblea 
"Papers": Revista de Sociologia

\section{FIGURA 1}

Modelos organizativos básicos de las OIGs

Modelo A ("Uniones" del siglo XIX; OTAN)

Asamblea Plenaria
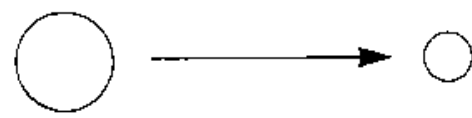

Secretariado

Modelo B (Instituciones especializadas del sistema de las NN.UU.)

Asamblea Plenaria

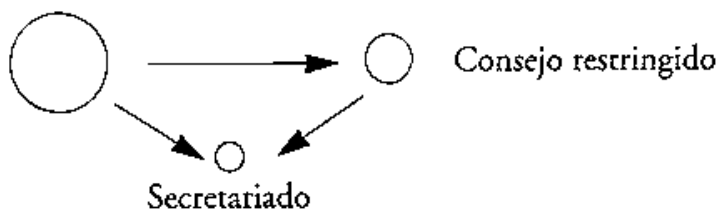

Modelo C (Consejo de Europa)

Consejo de Ministros

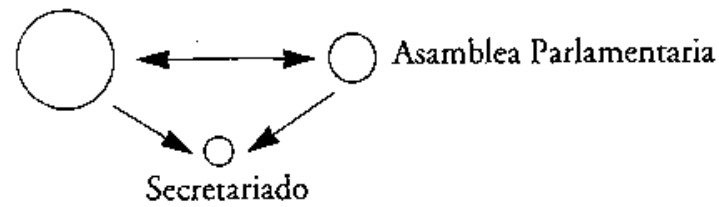

Modelo D (Comunidad Económica Europea)

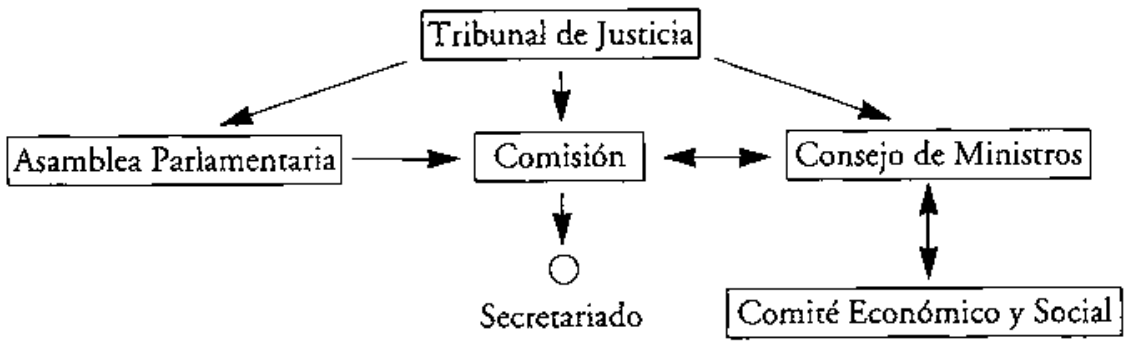

Fuente: Marcel Merle, Sociologie des relations internationalles, París, Dalloz, 1988 (4a 43d.), p. 367 . No se consideran los ótganos subsidiarios. 
FIGURA 2

Estructura típica de una OIG

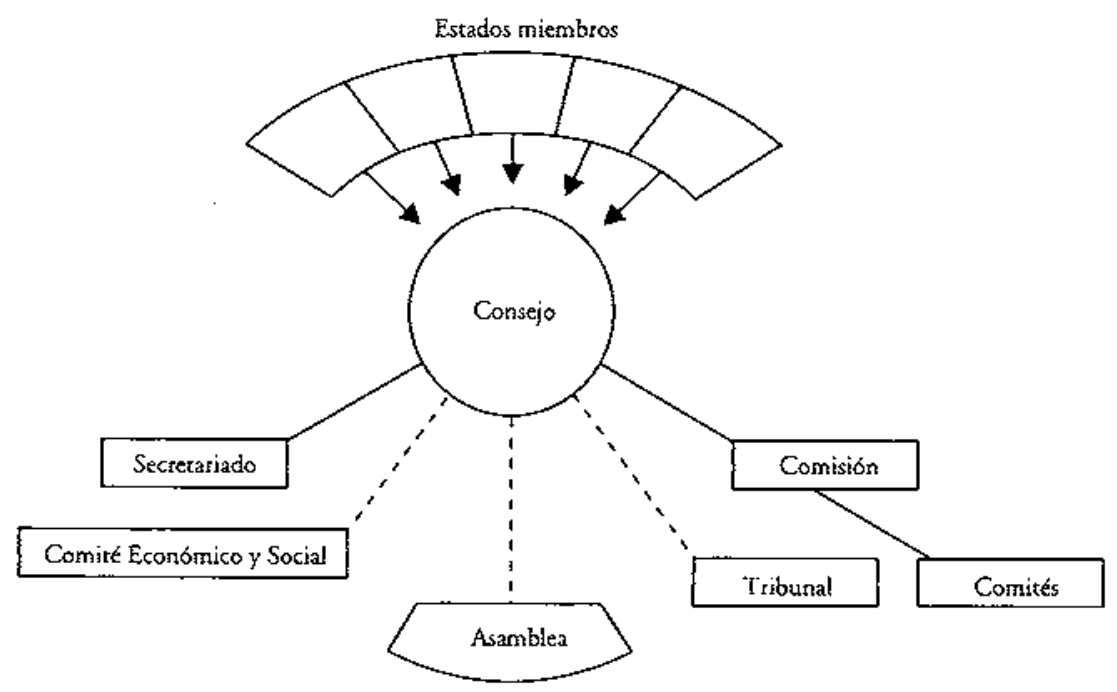

Insticuciones típicas de las OIGs. - - - - - Instituciones comunes a muchas OIGs

Fuente: Philip Taylor, Non-State Actors in International Politics. From Transregional to Substate Organizations (Westview Press, Boulder, 1983).

en el proceso de toma de decisiones. También los comités económicos y sociales actúan como órganos de asesoramiento y representación; además, a menudo sirven de espacio privilegiado para canalizar las funciones de cabildeo o lobbying de las diversas fuerzas e intereses representados en la organización. Por último, el Tribunal puede tomar formas muy diversas: ser poco más que un cuerpo de arbitraje, como ocurre en la Comunidad Económica de los estados de África occidertal; ser un órgano capacitado para dirimir disputar entre los diversos cuerpos de una organización y dictaminar sobre la "constitucionalidad" de una decisión o acto, como, por ejemplo, el Tribunal de Justicia de las Comunidades Europeas; o bien un tribunal que remite opiniones no vinculantes a los otros órganos importantes de la OIG, como sucede con el Tribunal Internacional de Justicia en las NN.UU.

Vamos a dejar de lado, empero, los rasgos comunes inferibles del examen de las estructuras organizativas de las OIGs y a centrarnos de nuevo en las diferencias, en los rasgos que permiten establecer tipologías. 
Tres son los principales elementos que, al estudiar las diversas estructuras organizativas de las OIGs, permiten establecer fracturas o líneas de separación de marcado interés politológico:

a) Las diferencias que puedan existir entre los miembros, es decir el tratamiento más o menos igualitario - de facto y no de iure - que se otorga a cada estado. Los factores a considerar pueden ir desde la posibilidad que tienen los miembros de pertenecer a determinados órganos/cargos (por ejemplo, quien puede ser miembro permanente del Consejo de Seguridad de las NN.UU. en virtud del principio manejado por las grandes potencias vencedoras de la II Guerra Mundial de estados iguales, responsabilidades desiguales") al mecanismo previsto para la toma de decisiones (votaciones por mayoría, procedimientos previstos para mayorías cualificadas, etc.).

b) El grado de independencia y capacidad de decisión de los diversos órganos de carácter «institucionaln, orientados a la gestión y defensa de los intereses colectivos de la organización, respecto de los estados miembros. Ello supone prestat atención especial a órganos como el Secretario General en el caso de las NN.UU., a los diversos secretariados, o la Co-

\section{TABLA 1}

División de las OIs en función de características estructurales

\begin{tabular}{|c|c|c|c|c|c|c|}
\hline \multirow[b]{3}{*}{ 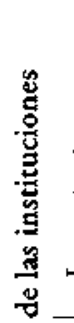 } & \multicolumn{6}{|c|}{ Dependencia de los estados miembros } \\
\hline & Importante & Menor & Importante & Menor & Impotzance & Menor \\
\hline & OTAN & Liga Árabe & OIT & EFTA & $\begin{array}{l}\text { Ejérciro } \\
\text { Salvación }\end{array}$ & $\begin{array}{l}\text { Asociación } \\
\text { Nórdica }\end{array}$ \\
\hline & FMI & $\begin{array}{l}\text { Sociedad } \\
\text { Naciones }\end{array}$ & CEE & CIUC & WWF & - \\
\hline z & \multicolumn{2}{|c|}{ Gubernamental } & \multicolumn{2}{|c|}{ Mixta } & \multicolumn{2}{|c|}{ No gubernamental } \\
\hline
\end{tabular}

Abreviaturas: CIUC, Consejo Internacional de Uniones Cientificas; OIT, Organización Internacional del Trabajo; WWF, World Wildife Fund.

Fuente: Archer 1992: 68. 
misión en el caso de las Comunidades Europeas. Para analizarlo, hay que recurrir a indicadores a menudo complejos o, al menos, no evidentes, que van desde mecanismos de control y presión indirectos como la reelección o no de ciertas personas para desempeñar determinados cargos, hasta los procedimientos de reparto geográfico, nacional u otro procedimiento preestablecido de reserva de "cuotas" para adjudicar los diversos cargos a cubrir en cada uno de dichos órganos.

c) El equilibrio existente entre los elementos gubernamentales y no gubernamentales, caso de existir, en las diversas OIs.

La combinación de esos tres elementos y sti aplicación taxonómica a diversas OIS a partir de ejes tan sencillos como grado importante o menor de presencia de elementos gubernamentales o no gubernamentales, naturaleza más o menos igualitaria de las instituciones y nivel de dependencia de los órganos e instituciones de los estados miembros, permite establecer clasificaciones muy ilustrativas, como la que se reproduce en la tabla 1.

Tras el rápido examen de los cuatro grandes criterios de clasificación de las OIGs (naturaleza de sus miembros, composición, objetivos y estructura) y de sus posibilidades, sólo falta recordar que esos criterios (u orros) pueden combinarse entre sí, dando lugar a tipologías que, pese a la inevitable simplificación, ayudan a elaborar un "mapa mental» de las diversas OIs existentes.

A continuación se reproduce un cuadro-resumen (Taylor Ph., 1984) de una de estas tipologías (véase tabla 2 en pág. 72 ). El cuadro combina tres criterios o rasgos distintivos en una matriz $4 \times 4$ : a) la diferencia entre OIG y $\mathrm{ONG}$; b) el ámbito geográfico al que pertenecen los miembros de la organización, regional y suprarregional; c) la actividad o función predominante de cada organización, con cuatto subdivisiones en la escala "general-específico": económica, de seguridad, política e ideológico-cultural.

Hay que señalar, empero, que el túltimo criterio, la actividad o función predominante, utiliza categorías flexibles. Así, bajo la denominación de OI "económica" se incluyen funciones muy diversas: relativas al comercio intragrupo, al desarrollo económico o a la reducción de la competencia económica disfuncional. La denominación "seguridad" contempla Ols que persiguen la seguridad mutua (alianzas) o bien sistemas de seguridad colectiva. La categoría de organización "política" es ambigua, en la medida en que, por lo general, se aplica a organizaciones plurifuncionales, es decir, no exclusivamente políticas. Por último, la etiqueta «ideológico-cultural» incluye grupos cuyos esfuerzos mancomunados se encaminan a preservar o ampliar vínculos filosóficos, religiosos, nacionales, étnicos, etcétera, de ahí que puedan ejercer funcionen semejantes a las de organizaciones políticas con las que mantienen vínculos. 
«Papers": Revista de Sociologia

\section{TABLA 2}

Ejemplo de tipología mixta de OIs

\begin{tabular}{|c|c|c|c|c|c|c|}
\hline & \multicolumn{4}{|c|}{ FUNCION/ACTIVIDADES } \\
\hline & & & Económica & Seguridad & Politica & Ideológico-Cultural \\
\hline \multirow{4}{*}{$\begin{array}{l}z \\
0 \\
0 \\
0 \\
0 \\
0 \\
0 \\
0\end{array}$} & \multirow{2}{*}{ 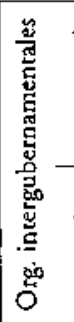 } & 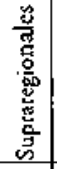 & $\begin{array}{l}\text { OCDE } \\
\text { OPEP } \\
\text { FMI } \\
\text { GATT }\end{array}$ & $\begin{array}{l}\text { OTAN } \\
\text { Consejo de } \\
\text { Seguridad } \\
\text { (ONU) }\end{array}$ & $\begin{array}{l}\text { Asamblea General } \\
\text { (ONU) } \\
\text { Commonwealth }\end{array}$ & Consejo İslárnico \\
\hline & & 岁 & $\begin{array}{l}\text { CEE } \\
\text { ASEAN } \\
\text { BERD } \\
\text { EFTA }\end{array}$ & $\begin{array}{l}\text { UEO } \\
\text { CENTO } \\
\text { ANZUS }\end{array}$ & $\begin{array}{l}\text { OUA } \\
\text { OEA } \\
\text { Consejo de Europa } \\
\text { Liga Arabe }\end{array}$ & $\begin{array}{l}\text { Consejo Nórdico } \\
\text { Unión Postal } \\
\text { Arabe }\end{array}$ \\
\hline & \multirow{2}{*}{ 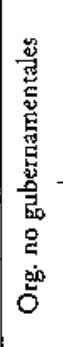 } & 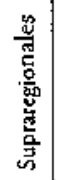 & $\begin{array}{l}\text { Cámara de } \\
\text { Cometcio } \\
\text { Internacional }\end{array}$ & $\begin{array}{l}\text { Unión Intes } \\
\text { Parlamentaria } \\
\text { IIES }\end{array}$ & $\begin{array}{l}\text { Inrernacional } \\
\text { Socialista } \\
\text { Internacional } \\
\text { Conservadora }\end{array}$ & $\begin{array}{l}\text { Cruz Roja } \\
\text { Amnistia } \\
\text { Internacional }\end{array}$ \\
\hline & & 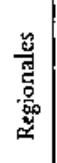 & $\begin{array}{l}\text { Unión Arabe de } \\
\text { Cámaras de } \\
\text { Comercio }\end{array}$ & $\begin{array}{l}\text { Liga de Defensa } \\
\text { Judía } \\
\text { IRA }\end{array}$ & $\begin{array}{l}\text { OLP } \\
\text { Unionde } \\
\text { Parlamentos } \\
\text { Africanos }\end{array}$ & $\begin{array}{l}\text { OXFAM } \\
\text { Ftères des } \\
\text { Hommes } \\
\text { Ayuda en Acción }\end{array}$ \\
\hline
\end{tabular}

Abreviaturas: OCDE, Organización de Cooperación y Desartoollo Económico; OPEP, Organización de Palses Exportadores de Petróleo; FMI, Fondo Monecario Internacional; GATT, Acuerdo General sobre Comercio y Aranceles; CEE, Conunidad Económica Europea; ASEAN, Asociación de Naciones del Sudeste Asiático; BERD, Banco Europeo de Reconstrucción y Desarrollo; EFTA, Asociación Europea de Libre Comercio; OTAN, Organización del Tratado del Atláncico Norte; UEO, Unión Europea Occidental; CENTO, Organización del Tratado Central; ANZUS, Pacto de Australia, Nueva Zelanda y EE.UU.; IRA, Ejército Revolucionario Irlandés; OUA, Organización para la Unidad Africana; OEA, Organización de Estados Americanos; OLP, Organización para la Liberación de Palestina.

Fuente: Philip Taylor, Non-State Actors in Intemational Politics, con modificaciones.

\section{LAS OIGS COMO ACTORES DEL SISTEMA INTERNACIONAL: PAPELES Y FUNCIONES}

Hasta el momento nos hemos limitado a definir y analizar el proceso de organizacion internacional y a definir y clasificar las OIs, pero no nos hemos ocupado todavía de establecer sus papeles y funciones en el sistema en relación a los restantes actores internacionales. Pudiera parecer que, habida 
cuenta de la proliferación de OIs, en un sentido "horizontal" (número) y "vertical" (incremento de funciones), resulta indiscutible que se trata de actores de gran importancia y autonomía, casi comparable a la de los estados, al menos en lo que concierne a las OIGs. Las cosas, empero, no son tan sencillas, como pone de manifiesto la variada y enfrentada gama de posturas existente entre analistas, políticos y funcionarios internacionales acerca de los papeles que pueden desempeñar las OIGs y su importancia como actores internacionales.

En un extremo podríamos situar a quienes sostienen, desde un realismo fuerte, que las OIGs son incapaces de resolver la mayor parte de los problemas internacionales (excepto algunos estrictamente técnicos), incluyendo muchos de los explicitados en sus propios tratados fundacionales o programas de actuación. Su papel en el sistema internacional sería, pues, poco significativo; una prolongación de los estados o, a lo sumo, un escenario en que los estados persiguen satisfacer los objetivos de sus políticas exteriores o convenir declaraciones de intenciones de naturaleza retórica. En suma, no serían auténticos sujetos de las relaciones internacionales, actores atutónomos independientes de los estados, sino objetos de ellas. El hecho de que, en ocasiones excepcionales, algunas OIGs desempeñen realmente funciones de cierta relevancia se explicaría también por su subordinación a los estados: la hegemonía que en dicha organización ejerce uno o varios de sus estados miembros, actores con una posición central en el sistema y capaces de hacer que la OIG trabaje pro domo sta.

En el otro extremo hallamos las tesis de quienes sostienen, desde posiciones teñidas de idealismo, que las OIGs son los únicos instrumentos capaces de superar los inconvenientes derivados del carácter "anárquico" del sistema y, en particular, los grandes problemas globales (políticos, económicos o medioambientales) a que se enfrenta en la actualidad. Mezclando a veces el plano fáctico (su actuación real, el ser) y el normativo-prescriptivo (su conducta deseable, el deber ser), sus partidarios suelen subrayar la autonomía de las OrGs, prestando escasa atención a las constricciones a su margen de maniobra derivado del papel de los estados y gobiernos (fundadores y miembros de dichas organizaciones). En síntesis, las OIGs serian sujetos y no sólo objetos de las relaciones internacionales, un rasgo que sería deseable que se reforzara aún más en el futuro.

Aunque la polémica sobre el papel de las OIGs es pertinente en el marco de la llamada discusión interparadigmática entre las diversas concepciones de las relaciones internacionales, donde cada enfoque suele enfatizar un "rol» y omitir los otros posibles, para analizar lo que realmente hacen las OIGs resulta más fructífero optar por una postura más ecléctica. De acuerdo con ella, tanto las dos posturas extremas a que hemos aludido como las diversas posiciones 
intermedias contienen elementos de verdad en sus descripciones. Es decir, buena parte de sus tesis pueden considerarse complementarias, a condición de no magnificarlas, de no tratar por igual todas las OIGs y de tomar en consideración el contexto temporal, la evolución del sistema.

Formulado en positivo, el "enfoque ecléctico» consideraría que las OIGs pueden desempeñar tres grandes papeles o funciones, que no han de concebirse como necesariamente excluyentes (Pentland, 1976: 8):

1) ser instrumentos para la realización de objetivos de la política exterior de los respectivos estados miembros;

2) servir de modificadores sistémicos de la conducta de los estados;

3) comportarse como actores internacionales autónomos.

En tanto que posibles instrumentos de la política exterior de sus miembros, las OIGs están sujetas a los cálculos de utilidad de los estados. Esos cátculos se encaminan a saber hasta qué punto y a qué coste pueden servir a sus objetivos, es decir, cómo pueden influir en la actuación de las OIGs - bien en solitario (unilateralmente), bien formando coaliciones con otros estados (multilateralmente) - para que éstas se comporten de forma favorable, o al menos no lesiva, a sus intereses. El cálculo ha de tomar en consideración dos factores: a) la capacidad y la voluntad de los estados de influir en las OIGs, que depende en buena medida de la posición que ocupa cada estado en el sistema; y b) el grado de utilizabilidad de cada OIG, que puede variar a lo largo del tiempo o en función del tema.

Lo cierto es que el análisis de la actuación de las OIGs muestra que "los casos de dominación evidente de una OIG por un sólo estado son excepcionales. Para la mayoría de estados, usar las OIGs para perseguir objetivos de política exrerior significa colaboración y no manipulación (aunque la distinción a menudo puede resultar muy sutil)" (Pentland, 1976: 6-7; la cursiva es mía). De ahí que lo fundamental sea crear o mantener coaliciones. Aunque el grado de institucionalización y cohesión de una coalición puede variar mucho, como resulta fácil comprobar si se observa su conducta en la Asamblea General de las NN.UU., se refleja siempre en las pautas de votación y en la toma de decisiones. El análisis de dichas pautas suele mostrar que las coaliciones son dinámicas y cambiantes, de manera que la divergencia dentro de agrupaciones de estados que suelen comportarse como aliados se incrementa si el asunto que se considera tiene una importancia menor.

En resumen, en tanto que instrumentos, las OIGs carecen de dirección u objetivos independientes de los emanados de sus miembros y sus estrategias de dominio. Es decir, las OlGs, habida cuenta de su nulo o escaso grado de autonomía, serían un simple escenario de interacción de los estados. 
No obstante, las OIGs pueden actuar y, por tanto, considerarse como eventuales modificadores sistémicos de la conducta de los estados. Las OIGs, aunque creadas por la voluntad colectiva de los estados, acaban condicionando las relaciones interestatales, tradicionalmente consideradas un terreno en que la única ley es el laissez faire. En ese sentido, serían una manifestación institucionalizada de las restricciones que el sistema internacional impone a los estados, restricciones que confieren a las OIGs un grado limitado pero importante de capacidad de actuación. No son ni simples instrumentos de los estados ni actores plenamente autonomos.

Esa capacidad de las OIGs depende en gran medida de factores externos a ellas, de las pautas de funcionamiento del sistema, a saber: de su grado de polarización, del status y jerarquía de los actores estatales, de su grado de interdependencia, etcétera. No obstante, hay que considerar también la influencia de ciertos rasgos de la propia OIG en su capacidad de influir en la conducta de los estados, como su programa de actuación, las características organizativas o el proceso de toma de decisiones. De otra forma resultaría imposible entender, por ejemplo, muchos aspectos de la relación de los EE.UU. con el sistema de las Naciones Unidas, desde sus amenazas de dejar de pagar su parte del presupuesto hasta su retirada de la Organización Internacional del Trabajo y de la UNESCO. Basta recordar que las primeras críticas de la Administración estadounidense se remontan a la época de John F. Kennedy, es decir, al momento en que el proceso de descolonización altera la correlación de fuerzas en la Asamblea General de las NN.UU. en favor de los países del Tercer Mundo.

Existe, por último, una tercera función posible de las OIGs, la de actores internacionales autónomos, con cierto grado de independencia y, por tanto, capaces de influir en los restantes actores y de resistirse a sus influencias. Autonomía y capacidad de influencia exigen un importante desarrollo organizativo y recursos considerables (información, presupuesto, capacidad de decisión, instrumentos operativos, etcétera).

De ahí que al buscar ejemplos de OIGs en condiciones de desempeñar el papel de actor autónomo se suela recurrir al sistema de las NN.UU. Al hacerlo suelen aducirse una o varias fuentes de influencia política: a) capacidad de regulación (organismos técnicos, especialmente en las comunicaciones, el transporte y la salud); b) capacidad ejecutiva (por ejemplo, en organismos especializados en asistencia técnica y operaciones financieras); c) conocimiento especializado (informes e investigaciones); y d) legitimación (aceptación de su actividad por parte de la opinión pública y de los gobiernos).

Si dejamos de lado los papeles posibles y examinamos globalmente la actuación concreta de las OIGs en las últimas décadas, to habitual es que coexistan los tres papeles ofunciones a que acabamos de referirnos. La razón de ello es que uen sus roles de instrumentos, fórums y actores desempeñan tareas 
que contribuyen al funcionamiento del sistema político internacional" (Archer, 1992: 178). Esa coexistencia, empero, no está exenta de tensiones, puesto que si bien las OIGs "alivian de aigunos problemas a los estados, también les crean otros nuevos. Y si, para el teórico, las OIGs aún no desafían el modelo de sistema internacional estatocéntrico, no puede negarse que en cierto modo lo complican y comprometen" (Pentland, 1976: 14).

Respecto del futuro, todo parece indicar, si atendemos a los hechos, que a medio plazo continuará manifestándose la coexistencia tensa entre las tres funciones. Dicho de otra manera, no parece previsible que haya un incremento notorio del papel de las OIGs como actores autónomos en detrimento det papel de los estados. No obstante, la urgencia de algunos desafíos globales, imposibles de resolver desde la óptica del simple interés particular, ha hecho que renazca el debare sobre la deseabilidad de tal cosa en el contexto de los grandes cambios que el sistema internacional ha experimentado a partir de la década de los ochenta.

\section{LAS OIGS Y LOS PROBLEMAS GLOBALES: LA DEGRADACION AMBIENTAL Y EL CAMBIO CLIMÁTICO}

Aunque la degradación ambiental, un problema aparentemente técnico (de low politics) no es el único problema global' de los que se han ocupado recientemente las OIGs, como muestra un examen de las conferencias especiales orgarizadas por las NN.UU. a partir de la decada de los setenta (Taylor/Groom, 1989), resulta especialmente pertinente para concluir nuestro análisis de las organizaciones internacionales por dos razones. Por un lado, la creciente relevancia de la agenda ambiental en las relaciones internacionales permite aprehender el carácter dúplice, conflictivo, del problema: se trata de un asunto claramente global pero, a la vez, políticamente divisivo en la medida en que el calentamiento global, el deterioro de la capa de ozono estratosférica, la lluvia ácida o la contaminación marina generan costes reales diferentes a los diversos estados $y$, por tanto, políticas nacionales a menudo enfrentadas. Ello plantea los límites $y$ virtualidades del posible papel conciliador o ejecutivo de las OIGs.

Por otro lado, el fin de la guerra fría y el enfrentamiento Este/Oeste, la difuminación de Moscú como polo del sistema y el resurgir de la diplomacia multilateral han generado un debate sobre el nuevo papel de las NN.UU. (véase el artículo de Sánchez en este mismo número). Aunque los asuntos centrales de ese debate son la reforma de la organización y la viabilidad de los

5. El control del crecimiento de la población, la producción y distribución de alimentos, el desarme, la discriminación racial, el desarrollo o la promoción de la mujer son algunos otros. 
mecanismos de seguridad colectiva en el sistema internacional de la postguerra fría, se plantea la posibilidad de que asuma nuevas funciones, en particular en el campo medioambiental.

Por consiguiente, los grandes problemas ambientales de la década de los noventa están claramente vinculados al debate sobre el papel futuro de las OIGs en nuestro mundo globalizado e interdependiente.

La preocupación ambiental de organizaciones como las NN.UU. es anterior a la reciente popularización del tema por los medios de comunicación. Así, en la conferencia de las NN.UU. sobre el Medio Humano (Estocolmo, 5-16 de junio de 1972) se aceptó el carácter global de los asuntos medioambientales y se decidió incrementar la investigación y la tarea de sensibilización de la opinión pública, razones de la creación, poco después de Estocolmo, del Programa de las Naciones Unidas para el Medio Ambiente (PNUMA). En los veinte años transcurridos desde Estocolmo hasta la Conferencia de las NN.UU. sobre el Medio Ambiente y el Desarrollo (Río de Janeiro, 3-14 de junio de 1992), se ha producido un cambio de percepción importante, al que no es ajeno el trabajo del PNUMA.

Ese cambio podría sintetizarse, de forma esquemática, así:

a) agudización de la conciencia de degradación ambiental y aceptación del derecho de las generaciones futuras a los recursos, limitados, de la biosfera;

b) elaboración de una agenda de grandes problemas ambientales (véase tabla 3 en pág. 78) en la que destacan, por su impacto en las relaciones internacionales, los asuntos relacionados con el cambio climático global, la degradación de recursos y la pérdida de diversidad biológica;

c) consideración de que, a causa de la difuminación de la distinción entre "alta política" y "política menor", la solución a los problemas ambientales no podrá ser meramente técnica, científica, sino también política;

d) interconexión de los asuntos ambientales con el desarrollo y también, al aumentar el riesgo de conflictividad ligada a la escasez y degradación de recursos, la seguridad.

Una de las consecuencias de ese cambio de percepción fue la decisión de la Asamblea General de las NN.UU. de crear una Comisión Mundial sobre el Medio Ambiente y el Desarrollo (1983), que presentó las conclusiones de su trabajo, el ya célebre Nuestro futuro comtin o Informe Brundtland, a la $42^{2}$ sesión de dicha Asamblea (1987).

El informe acuñó un término, "desarrollo sostenible», que pretendía señaLar los riesgos de las actuales formas de crecimiento y desarrollo económicos y evocar la necesidad de una transición hacia un futuro seguro, sustentable, 
"Papers": Revista de Sociologia

TABLA 3

La agenda ambiental para el 2000

I. El cambio climático y sus diversos impactos

I. Emisión de gases que provocan el efecto invernadero y calentamiento global de la atmósfera.

2. Deterioro de la capa de ozono estratosférica e incremento de la radiación ultravioleta y de sus efectos biocidas

3. Lluvias ácidas

II. Degradación de la tierra y el agua

4. Deforestación

5. Desertificación y degradación del suelo

6. Contaminación y reducción progresiva de los recursos acuáticos

III. Recursos genéticos y biológicos

7. Mantenimiento de la diversidad biológica (biodiversidad)

8. Captura abusiva de algunos tecursos bióticos de origen animal

IV. Residuos peligrosos

9. Problemas de reciclado y de almacenaje con garantías

10. Movimientos transfronterizos y "exportación" de residuos

V. Impacto de nuevos materiales y tecnologías

11. Biotecnología: impacto en la biodiversidad (sobre todo en la agricultura)

12. Uso de megatecnologias para alterar el medio ambiente

Fuente: Elaborado a partir de The State of the World Environment 1989 (UNEP/CG 15/7/AAd.2), 1989 $y$ de Global Outlook 2000. An Economic. Social and Environmental Perspective, Nueva York, The United Nations Publications, 1990.

para la comunidad humana. Concretamente, se argüía que para garantizar el carácter sostenible del cesarrollo de la humanidad han de introducirse límites (aunque no absolutos) al uso de los recursos; de lo contratio resulta imposible asegurar un desarrollo "que satisfaga las necesidades del presente sin comprometer la capacidad de las futuras generaciones para satisfacer las propias». En línea con la vinculación entre medio ambiente y desarrollo, el Informe planteaba la urgencia de hacer frente a la pobreza, habida cuenta que el desarrollo sostenible ha de colmar las aspiraciones de todos a una vida mejor: «un mundo donde la pobreza es endémica será siempre propenso a sufrir una catástrofe ecológica" (Brundtland, 1987: 29).

El vínculo entre subdesarrollo y deterioro del medio ambiente alertaba a su vez del enorme potencial de tensiones y conflictos presente en la dimensión ambiental, de la telación entre medio ambiente y seguridad, en una doble dirección. En primer lugar, a propósito de la relación entre países desar- 
rollados y países en vías de desarrollo, entre lo que se ha dado en llamar Norte y Sur. En segundo, respecto del previsible incremento de los conflictos ligados a recursos naturales escasos o en vías de rápida degradación, que afecta muy en particular a la conflictividad entre los países en vías de desarrollo, la conflictividad intra-sur.

Respecto de la conflictividad intra-sur, resulta paradigmático el caso del agua. Veamos, por ejemplo, algunos datos sobre recursos fluviales compartidos entre diversos países. Sólo en África nos encontramos con cursos de agua que fluyen a lo largo de diez países (Níger), nueve (Nilo) u ocho (Zambezi). Basta con tomar el caso del Nilo para percatarse de los riesgos de conflicto: desde tiempo inmemorial Egipto es el principal usuario del agua del Nilo, Sudán algo así como un intermediario, y Etiopía y Uganda quienes controlan la cabecera de la cuenca. El potencial de escalada bélica se refleja claramente en unas palabras pronunciadas en 1978 por el entonces presidente egipcio Anuar El Sadat a propósito de la pretensión etíope de construir presas en la cabecera del Nilo: «si alguien piensa en algún momento privarnos de nuestra vida, no dudaremos en ir a la guerra".

No obstante, el riesgo de conflictividad afecta también a ríos que fluyen por menos países, como pone de manifiesto el caso del tío Senegal y las tensiones existentes entre Mauritania y Senegal. Por otro lado, el problema global de falta de agua va a ser acuciante. Una estimación reciente señala que hacia el año 2000 unos treinta millones de personas podría vivir en estados con importantes problemas de recursos hídricos y unos ciento cincuenta millones en países afectados de una escasez absoluta de agua ${ }^{6}$.

En cuanto a las diferencias y tensiones entre los países del Norte y el Sur a propósito de la forma de abordar los problemas ambientales, hay que señalar de entrada que vienen de lejos. Se manifestaron ya en Estocolmo, donde Indira Gandhi afirmó que "los problemas ambientales de los países en desarrollo no son efectos colaterales de la industrialización excesiva, sino el reflejo de la inadecuación del desarrollon. Recientemente, la creciente actividad de las OIGs acerca de problemas como el cambio climático global o la pérdida de biodiversidad han puesto de manifiesto un incremento de las tensiones. Un repaso de lo sucedido en las negociaciones de acuerdos para proteger la capa de ozono auspiciadas por el PNUMA (Convención de Viena, 1985; Protocolo de Montreal, 1987; Declaración de Helsinki, 1989) o el debate generado por el Informe Brundland y las medidas ulteriores de las NN.UU., como la convocatoria y preparación de la conferencia de Río, proporcionan abundantes ejemplos.

6. Véase al respecto M. Falkenmark, "New Ecological Approach to the Water Cycle", Ambio, vol. XIII, núm. 3, 1984, pp. 152-160; tambien R. Clarke, Water: the International Crisis, Londres, Earthscan, 1991. 
Especialmente útil para comprender la virulencia de las tensiones y enfrentamientos entre el Norte y el Sur resulta la preparación y realización de la Conferencia de Río de Janeiro, convocada por actuerdo de la Asamblea General (diciembre de 1989). Su objetivo inicial era que jefes de estado o de gobierno adoptasen en ella las decisiones necesarias para emprender la transición a un desarrollo ambiental bien fundamentado y sostenible, compatible con las conclusiones del Informe Brundtland. Para ello, y a diferencia de Estocolmo, se consideraba preciso alcanzar acuerdos jurídicamente vinculantes y establecer mecanismos adecuados de seguimiento y control.

No obstante, tanto en la fase previa como en la propia Conferencia se vislumbró la enorme dificultad (para algunos, imposibilidad) de mantener simultáneamente, al menos en el terreno de las medidas prácticas, tres cosas que el Informe Bundtland consideraba conciliables: el actual modelo de crecimiento económico de los países desarrollados, el respeto por el medio ambiente y el fomento del crecimiento y desarrollo de los países del Sur. Dicho de otra manera, si bien es obvio que los límites de la biosfera no permiten la generalización de las pautas de vida y consumo de los países más desarrollados a los más de cinco mil millones de habitantes del planeta, tampoco puede congelarse y perpetuarse el actual abismo entre el Norte y el Sur.

Veamos dos ejemplos, ambos motivo de enfrentamiento en Río, ia deforestación y la emisión de gases que favorecen el calentamiento global (efecto invernadero) y el cambio climático.

Es bien conocida la preocupación por los efectos de la creciente deforestación, sobre todo en las zonas tropicales, donde la tasa anual de pérdida de superficies boscosas supera los dieciséis millones de hectáreas. La deforestación tropical agrava el efecto invernadero y la pérdida de diversidad biológica, aumenta la erosión, altera el balance hídrico y afecta a centenares de millones de personas (inundaciones, sequía, escasez de leña, desplazamiento de población). A primera vista sus principales causantes son los países del Sur (Brasil, Colombia, México, Costa de Marfil, Nigeria, Indonesia, Tailandia, Zaire, Venezuela o Ecuador tienen tasas de deforestación superiores a cien mil hectáreas anuales). No obstante, en Río los países del Sur recordaron su responsabilidad a los países del Norte, al señalar la clara conexión entre país deforestador y país con fuerte deuda externa (entre los países más endeudados figuraban a finales de los años ochenta buena parte de los anteriormente citados como deforestadores), la voracidad de algunas empresas transnacionales o el consumo desmedido de maderas tropicales en Japón o la CEE.

Así las cosas, no resulta extraño que en Río se acabara firmando un documento, sin valor jurídico vinculante, ambiguo y que en el futuro podrá invocarse con intencionalidades antitéticas: reconoce a las naciones en desarrollo su soberanía en el empleo de los recursos forestales, apunta la necesidad de re- 
gular el comercio internacional de madera y evita delimitar de forma concreta los asuntos de deforestación.

Con respecto al riesgo de calentamiento de la atmósfera en virtud de las emisiones de los gases que provocan el efecto invernadero, y en particular las de dióxido de carbono $\left(\mathrm{CO}^{2}\right)$, basta recordar que se ha calculado que las causas básicas son la quema de combustibles fósiles (más de cinco mil millones de toneladas al año) y la deforestación (entre seiscientos y dos mil millones de toneladas al año). Ello quiere decir que, a diferencia de la deforestación, buena parte del problema proviene del Norte: el $75 \%$ de esas emisiones procede de siete países desarrollados. De ese total, a Japón, EE.UU. y la CEE les corresponden respectivamente un $25 \%, 23 \%$ y $13 \%$.

Hubo discrepancias serias respecto de los objetivos (congelar o reducir), los plazos para lograrlos y la forma de financiar las actuaciones encaminadas a alcanzarlos. La CEE, por ejemplo, hizo las propuestas más ambiciosas por parte de los países altamente desarrollados: lograr en el año 2000 que las emisiones fueran iguales a las de 1990 y crear un impuesto energético en los países de la OCDE (a lo que de momento se oponen algunos estados miembros como España). Frente a ellas, algunos países del Sur y, sobre todo, las ONGs propusieron que la meta para el 2000 fuera una reducción del $20 \%$ de las emisiones de $\mathrm{CO}^{2}$ de los países industrializados. El enfrentamiento y, en especial, las reticencias a comprometerse por parte de algunos países del Norte, explican que finalmente el "Convenio marco de las NN.UU. sobre el cambio climáticon firmado en Río no defina objetivos cuantitativos ni establezca calendario vinculante para la reducción de las emisiones de dióxido de carbono.

Los dos ejemplos anteriores permiten extraer conclusiones acerca del impacto que las tensiones entre el Norte y el Sur acerca de la forma de abordar La relación entre medio ambiente y desarrollo tienen en la asunción de responsabilidades por parte de las OIGs en materia ambiental. Concretamente, puede afirmarse que dichas tensiones obstaculizan seriamente la adopción de los dos compromisos imprescindibles para que las OIGs puedan ocuparse eficazmente de la gestión de los problemas ambientales globales: un fuerte incremento de los recursos financieros disponibles para tales fines y un alto grado de institucionalización organizativa.

Buena prueba de ello son los resultados, vinculantes y no vinculantes, obtenidos en Río de Janeiro. Por un lado, los dos convenios vinculantes sobre cambio climático y sobre biodiversidad, son bastante ambiguos o inconcretos. Este último, además, ni siquiera fue firmado por el país que cuenta con la mayor industria biotecnológica del mundo, los EE.UU. (lo ha hecho en 1993). El Convenio sobre la Diversidad Biológica, por ejemplo, es poco más que un instrumento marco; aunque alude a la necesidad de financiar al Sur para pro- 
"Papers": Revista de Sociologia

teger sus recursos de diversidad biológica, ni fija ni cuantifica ayudas para la protección, ni establece las áreas a proteger o listas de especies.

Por su parte, los principales resultados no vinculanres, la Declaración de Río y el Programa 21, si bien establecen principios, estrategias, iniciativas y recomendaciones de gran interés (pese a que algunas fueron descafeinadas en el proceso de negociación), la falta de compromisos respecto de los recursos financieros y la institucionalización hace que su utilidad dependa de las decisiones que los gobiernos tomen en los próximos años.

En cuanto a los recursos financieros, la ONU ha estimado que el cosco del Programa 21 no es inferior a 600.000 millones de dólares, de los que 125.000 deberán ser aportados por los países donantes y las instituciones crediticias inrernacionales. No obstante, las referencias concretas sobre la forma de lograrlo son muy vagas y conocidas: gastar el $0,7 \%$ del PIB en programas de ayuda en el año 2000 o cuando sea posible. La gestión de los fondos quedaría en manos del Fondo Global para el Ambiente (dependiente del Banco Mundial), organismos de NN.UU., bancos regionales y asistencia bilateral.

En cuanto a las recomendaciones institucionales, el capítulo 38 del Programa 21 ("International Institutional Arrangements") enumera, a modo de recomendación, numerosos componentes institucionales posibles y, en particular, una Comisión de Desarrollo Sostenible bajo los auspicios del Comité Económico y Social de las NN.UU. Las tareas de ta Comisión son ambiciosas: el seguimiento de la Conferencia, la mejora de la cooperación internacional, la racionalización de la capacidad decisora de los gobiernos para integrar los temas de medio ambiente y desarrollo $y$, por úlrimo, el examen de los progresos realizados en la aplicación del Programa 21 a nivel nacional, regional e internacional.

En definitiva, el Comité habrá de buscar la eimplicación activa de los 6rganos, programas y organizaciones del sistema de las NN.UU., instituciones financieras internacionales y otras OIGs relevantes, así como fomentar la participación de ONGs, incluyendo la industria y el mundo empresarial así como las comunidades científicas". Ahora bien, lo que pueda hacer el Comité dependerá de la voluntad y recursos que le concedan los estados y los órganos de las NN.UU. Su eficacia, pues, está por ver.

Aunque se ha ido más lejos que en Estocolmo, se ha vuelto a eludir la creación de una organización específica con competencias operativas o bien de una estructura clara que permita centralizar la política ambiental global. Hay que concluir por tanto que, hoy por hoy, no puede afirmarse con certeza que en un futuro próximo las OIGs, y en particular el sistema de las NN.UU., estén en condiciones de convertirse en un actor autónomo decisivo en la gestión y resolución de los problemas ambientales globales.

La conclusión nos devuelve al punto de partida, la relación entre el proceso de organización internacional y el crecimiento de las organizaciones interna- 
cionales, en particular a la naturaleza ambivalente e incierta de éstas últimas como actores internacionales. Por decirlo con unas palabras prudentes y ponderadas de hace treinta años, el crecimiento de las Ols puede interpretarse en un sentido mínimo y máximo, uen su sentido mínimo ese crecimiento sugiere que los estadistas tienen mayor voluntad de poner el énfasis en los enfoques colectivos y no en los simplemente unilaterales en una amplia gama de asuntos. En su sentido máximo, puede presagiar el desarrollo de un sistema de gestión de las relaciones internacionales más eficaz del que nunca antes haya conocido el mundo. Al promover la proliferación de organismos internacionales y una mayor variedad y alcance de sus actividades, los estados ni garantizan ese resultado ni proporcionan evidencia irrefutable de su empeño en lograrlo, pero al menos abren la posibilidad de su consecución" (Claude, 1972: 286).

\section{REFERENCLAS BIBLIOGRÁFICAS}

Archer C. (1992), International Organizations, Londres, Routledge and Kegan (2a edición; la $I^{2}$ es de 1983).

Brundtland, G.H. (presidenta) (1987), Nuestro futuro común, Madrid, Alianza.

Bull, $\mathrm{H}$ y Watson, A. (compiladores) (1984), The Expansion of International Society, Oxford, Clarendon Press.

Cantori L.J. y Spiegel S.L (1970), The International Politics of Regions. A Comparative Approach, Englewood Cliffs, Prentice-Hall.

Claude I.L. (1964), Swords into Plowshares, Nueva York, Random House.

Claude, I. L. (1972), "The Growth of International Institutions", en Porter, B. (compilador), The Aberystuyth Papers, Londres, Oxford U.P., 1972.

Colliard D. (1985), Institutions des relations internationales, París, Dalloz (8a edición) (Existe edición castellana de la $6^{2}$ edición francesa, México, FCE, 1978).

Diehl P. F. (compilador) (1989), The Politics of International Organizations. Patterns and Insights, Chicago, Dorsey Press.

Merle, M. (1988), Sociologie des relations internationales, París, Dalloz (existe edición castellana de Alianza edirorial, 1991).

Osmanczyk, E.j. (1990), Encylopedia of the United Nations and International Agreements, Londres, Taylor \& Francis, $2^{a}$ edición, revisada y aumentada (existe versión castellana de la $1^{a}$ edición, México, FCE).

Pentland, Ch. (1976), "International Organizations and their Roles", en Rosenau, J., Thompson, K., Boyd, G. (compiladores), Wold Politics, Nueva York, The Free Press, 1976. (Reproducido también en Diehl 1989, pp. 5-14, edición a la que coresponden las citas).

Reuter, P. (1958), International Institutions, Londres, Allen and Unwin. 
"Papers»: Revista de Sociologia

Taylor, P. y Groom, AJR (1988), International institutions at work, Londres, Pinter Publishers.

Taylor, P. y Groom, AJR (1989), Global Issues in the United Nations Framework, Londres, Macmillan.

Taylor Ph. (1984), Non-state Actors in International Politics. From Transregional to Substate Organizations, Boulder, Westview.

Watson, A. (1992), The evolution of international society, Londres, Routledge and Kegan.

Whight, M. (1977), "The states-system of Hellas", en Whight, M., Systems of states, Leicester, Leicester University Press, 1977, pp. 46-72.

Woolf, L. (1916), Intermational Government, Londres, Allen and Unwin. 